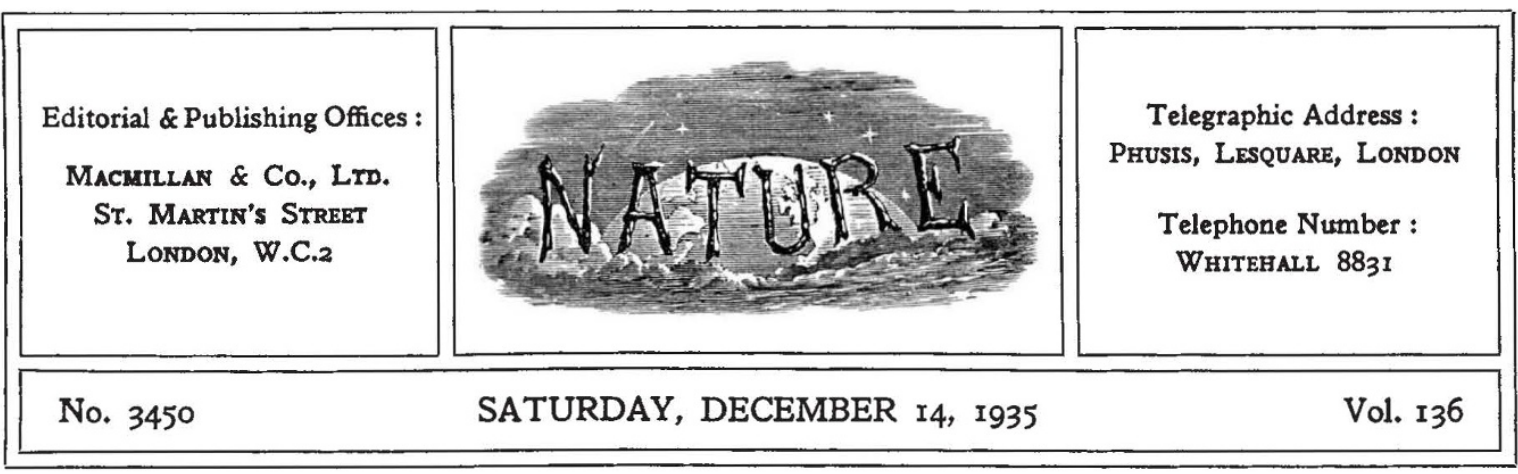

\title{
Nazi-Socialism and International Science
}

E VENTS of the past few years have accustomed us to the knowledge that the position of 'non-Aryan' scientific colleagues in official positions in the German Reich has become intolerable, even in the few cases where they have not been expelled from office. Now a new situation is developing which may be fraught with considerable danger to the continued co-operation of workers in other countries with their German colleagues. This new development carried to the limit can only result in the isolation of German men of science in all matters of international organisation.

The unwelcome move, to which attention bas been directed in a recent issue of the Basler National Zeitung, is the use that the Nazi authorities intend to make of international congresses for their own purposes. The Reichsminister of Propaganda has created a 'Science Congress Centre' (Wissenschaftliche Kongres-zentrale), one of the objects of which is to use scientific congresses as opportunities to influence public opinion through the medium of the important persons attending. No longer is this to be left to the chance of personal and friendly relations between the foreigners and the Germans present, but, where possible, steps are to be taken to introduce ideas of a Nazi-socialistic stamp into the discussions of matters of world moment.

For meetings held in Germany, the new centre would act as an intermediary between the Government and party officials on one hand, and the president and officers of the congress on the other. The programmes of the meeting and the lists of speakers would be subject to the approval of the centre: thus international conferences held in Germany are to be sifted of undesirable elements by the authorities beforehand and to survive as meetings approved by the Nazi party. For meetings held outside Germany the control must necessarily be much less, but here too it is possible to influence matters by sending German members to a meeting as a delegation under an appointed leader chosen for his reliability as a member of the Nazi party.

The meeting of the Astronomische Gesellschaft held at Berne last summer may be cited as an example of the working of the new machine. The Astronomische Gesellschaft is a long-established body with headquarters in Germany but with strong international affiliations, which have been particularly stressed by the Germans in recent years. One of the valued secretaries of the Astronomische Gesellschaft came up for re-election at the meeting and in the ordinary course of events would have been re-elected without question : on purely scientific grounds there was every reason for his continuance in office. This was, however, against the views of the German delegation, whose members were instructed not to vote for a Jew : alternative names were put forward and it became clear in the course of the meeting that something more vital was at stake than the question as to the holder of a particular office ; in fact, nothing less was at issue than the question whether an organisation of international standing and repute should come under the control of an anti-Semitic clique. When the vote was ultimately taken by secret ballot, it was found that the Nazi element had failed in its attempt, and the threatened secession of non-Germans from the Astronomische Gesellschaft was averted for the time. But the danger of subsequent development remains a source 
of anxiety to those concerned in international scientific relations.

It should be added in fairness to the Germans that internal persecution of a minority is not limited to their country, nor even the use of international gatherings to spread nationalist political propaganda. Both these undesirable practices are to be found in more than one country: we have no sympathy for either. But when these tendencies spread and a nationalistic movement tries to secure the control of international scientific work, it is time to call a halt.

\section{Health and Safety in Industry*}

$\mathrm{T}^{\mathrm{H}}$ HE report of the Chief Inspector of Factories and Workshops for 1934 gives some interesting illustrations of the part which science has still to play in the prevention of industrial accidents and the safeguarding of industrial health. Scientific investigation is, of course, a main factor in the con. tinuous improvement of processes so that operating conditions more and more eliminate dangers to health from noxious fumes or poisonous substances.

It is not, however, the field for further investigation which is here presented or the lack of exact knowledge of the effects of many well-known substances, particularly their cumulative effect, that is most impressive in the present report. Welcome as may be the evidence of the painstaking effort in this field to track down causes and to foresee possible dangers, a good deal remains to be done to secure effective co-operation and co-ordination between different branches of science, as well as between employer and employee.

The further we advance in this field of industrial health, the more important voluntary effort and the less effective legal compulsion become to secure the ends in view. Scientific research must supply the exact knowledge upon which effective action is based. Then comes the problem of securing that effective action is taken, and in this matter the co-operation of the employer and employee is essential. Once more, however, the report provides evidence that only continuous and expert supervision can ensure that co-operation is unbroken either by ignorance, indifference or neglect, whether studied or involuntary.

What is required is not merely the supervision exercised by inspectors of factories, but also the close and continuous oversight which can only be exercised by a scientific personnel in industry. Where in this way expert knowledge and a trained

* Annual Report of the Chief Inspector of Factorles and Workshops for the Year 1934. (London: H. M. Stationery Office, 1935.) (Cmd. 4931.) 2 s. mind can be brought to bear on the design of plant or development of processes from the point of view of the health and safety of those operating them, and still more on any unforeseen emergency which may arise, the risk of untoward injury to health is largely reduced. Where scientific personnel is absent or too heavily charged with other duties to exercise such oversight, the risks are correspondingly greater; the report refers, for example, to a factory in which all the processes entailing the most serious risks, were carried out by a proprietor who had a scientific training and the necessary knowledge and skill to avoid serious injury. So long as this process (the manufacture of hydrogen cyanide) can be kept in the hands of persons with the requisite knowledge it appears that the danger of the process can be controlled; but as a result of increased demand for the acid, the manufacture may possibly fall into the hands of inexperienced persons, with consequent risk.

This reference alone demonstrates sufficiently that it is not only in the manufacture of pharmaceutical preparations intended for the internal treatment of human ailments that properly qualified supervision is required in the public interest. There are many other processes and operations which equally demand the personal control of a properly qualified chemist, engineer, physicist or other scientific worker or technician, and this is a matter which demands the continuous attention of the professional organisations of chemists and others.

Equally impressive, however, is the picture the report supplies of the need for co-operation, and particularly on the medical side. Much of the value of medical supervision is lost because of the lack of knowledge of many general practitioners of the work of the medical inspectorate of factories, of factory legislation and of diseases of industry. The psychological effects of ill-founded sickness certificates "due to employment" are far-reaching 